DOI 10.37882/2500-3682.2021.08.05

\title{
ПЕРСПЕКТИВЫ РАЗВИТИЯ ГУМАНИТАРНОЙ КУЛЬТУРЫ СОВРЕМЕННОСТИ: ОТ «ИСТОРИИ ИДЕЙ» К ПОЭТИКЕ ИНТЕЛЛЕКТУАЛЬНОГО ДИСКУРСА
}

\section{PROSPECTS FOR THE DEVELOPMENT OF MODERN HUMANITARIAN CULTURE: FROM THE "HISTORY OF IDEAS" TOWARDS THE POETICS OF INTELLECTUAL DISCOURSE}

A. Enikeev

Summary: The article is devoted to the analysis of the problem of the development of humanitarian culture. The subject of the research is the concept of S. Zenkin, who identifies the following components of the intellectual discourse of modernity: the history of ideas, the mental scheme, the conceptual frame. As a methodology, "slow reading» is used, which creates an event-based context for understanding the cultural situation. It is concluded that the philosophical reading of the cultural text helps to create a context for understanding the cultural and intellectual situation in modern Russia.

Keywords: humanitarian culture, history of ideas, intellectual discourse mental scheme, conceptual frame.

\section{Введение}

W уманитарная культура современности характеризуется повышенным вниманием к теоретическим и методологическим основаниям собственного дискурса. Во многом это определяется идейной (а возможно и идеологической) исчерпанностью арсенала используемых в гуманитарных науках средств «аутопойэсиса», хотя есть предположение, что речь здесь идет всего лишь об «обновлении смыслов» современной гуманитарной практики. В этой связи заслуживает внимание работа, проделанная С. Зенкиным для обоснования теоретических положений современного гуманитарного дискурса. Современный исследователь, считает С. Зенкин, должен принимать в расчет как «концептуальное содержание идей» своих предшественников, так и «суггестивно-эвристическую силу метафор», используемых ими. Только тогда он сможет создать те «мыслительные схемы», которые позволят ему «встать на плечи» своих предшественников-гигантов и увидеть новые горизонты развертывания теории [7; 6].

Задача нашего исследования - проследить движение мысли С. Зенкина в вопросе о специфике интеллектуального дискурса, описать основные этапы

\author{
Еникеев Анатолий Анатольевич \\ К.ф.н., дочент, Кубанский государственный аграрный \\ университет им. И.Т. Трубилина (г. Краснодар) \\ rizoma69@yandex.ru
}

Аннотация: Статья посвящена анализу проблемы развития гуманитарной культуры. В качестве предмета исследования используется концепция С. Зенкина, который выделяет следующие компоненты интеллектуального дискурса современности: история идей, мыслительная схема, концептуальный фрейм. В качестве методологии используется «медленное чтение», создающее событийный контекст понимания культурной ситуации. Делается вывод, что философское прочтение культурного текста помогает создать контекст для понимания культурной и интеллектуальной ситуации в современной России.

Ключевые слова: гуманитарная культура, история идей, интеллектуальный дискурс, мыслительная схема, концептуальный фрейм. развития «истории идей», обозначить перспективы развития гуманитарной культуры современности. В качестве методологического подхода нами будет использована «идеология аллегорического чтения» П. де Мана, который призывал обращать внимание на риторику, а не на грамматику читаемого текста [8; 7]. Также определенную ценность для нас представляет подход В. Подороги, призывающего к «медленному чтению» [10; 22] философских текстов. И, конечно, методологически убедительными представляются взгляды на чтение и анализ философского текста со стороны В. Бибихина, который настаивает, что философское чтение должно быть «событием» $[1 ; 13]$. Предметом исследования или своеобразным «событием чтения» для нас выступает текст С. Зенкина «Работы о теории» (2012), который является итогом многолетних практик автора в области формирования интеллектуального дискурса современной России, а также ценным пособием по пониманию логики развития «теории» в качестве значимого концепта гуманитарной культуры. Значимость процедуры чтения определяется для нас возможностью понять поэтику философского текста, определить прагматические особенности функционирования текста в культуре, а также характер позиционирования философских идей в современном обществе [6]. 


\section{1. История ихей в прочессе формирования интемектуального Аискурса современности}

Собственный метод (способ действия) С. Зенкин определяет следующим образом. «Анализ сделанного прежде - для меня нечто большее, чем обычная в научном исследовании «история вопроса»: это всякий раз попытка с помощью чужой мысли мобилизовать какието продуктивные механизмы собственного мышления и применить их к исследованию предметов, о которых еще не думали предшественники» [7; 8]. Такой метод можно назвать «взыскательной герменевтикой, понимающей критикой», именно он позволяет наиболее аутентичным образом переосмыслить предшествующую «историю идей». «Для меня герменевтика теории - это не только интеллектуальная история современности, но и аутогерменевтика, работа интеллектуального самопознания» [7; 8]. Ниже мы рассмотрим основные «мыслительные схемы», которые обнаружил С. Зенкин при анализе особенностей современного гуманитарного дискурса в его теоретических основаниях.

Истоками гуманитарных проблем XX века было методологическое разделение на «объяснительные» и «понимающие» механизмы культуры, которые предопределили логику (и теорию аргументации) развития гуманитарных наук. В сердцевине данной парадигмы оказалась философия, которая не только не пожелала в полной мере освоить методы естественных наук, но и постоянно намекала на собственный «ненаучный» статус. Вполне закономерно поэтому, по мысли С. Зенкина, что «...к концу столетия в ней оказались четко противопоставлены друг другу два типа мысли: с одной стороны, аналитическая философия как рефлексия «естественнонаучного» типа... и деконструкция - рефлексия над традицией, изощренное переосмысление текстов, требующих понимания и пере-понимания, поскольку эти классические тексты сформировали наше собственное сознание» [7; 14]. Таким образом, Э. Дюркгейм и В. Дильтей оказались теми «отцами-основателями» гуманитарного дискурса современности, чье наследие до сих пор подвергается творческому переосмыслению и переоценке.

Казалось бы, соединение двух методологических парадигм невозможно, однако широкое распространение герменевтических процедур понимания (в том числе фактической реальности), создало более широкое пространство теоретического диалога, ведь «...и герменевтика также исходит из того, что смысл, сколь угодно сложный сам по себе, скрывается в отдельном тексте или символе, требующем понимания... В этом пункте позитивистская и философская история культуры смыкаются между собой. Эта двуединая историческая парадигма долгое время была определяющей для всего цикла гуманитарных наук, формируя базовую модель знания о человеке и обществе» [7; 17]. Процесс осмысления (наделения фактов смыслом) - это важнейший процесс производства гуманитарно-ориентированного знания и здесь встречаются два, на первый взгляд исключающие друг друга, процесса - субъективная интерпретация фактов и стремление к объективной «нормативизации дискурса». Нормативизм и дескриптивность гуманитарного дискурса современности находят общее пространство взаимодействия в «теории», как ее понимает С. Зенкин. «Такова, в общих чертах, ситуация гуманитарного знания, и многие передовые течения в гуманитарных науках нашего времени связаны именно с попытками помыслить, смоделировать с разных сторон такого рода объекты. В этих попытках упраздняется вековое противопоставление (спекулятивной) философии и (позитивистской) филологии; эти две дисциплины вступают в союз в рамках нового, весьма проблематичного рода научной деятельности, который иногда называют, за неимением более точного термина, теорией» [7; 18]. Таким образом, именно «теория» становится предметом исследования в работе C. Зенкина, она является наиболее значимым ориентиром развития гуманитарного знания XX века.

Теория развивается как практика осмысления идей, значимых для той или иной культурной и исторической эпохи. Социальные и культурные особенности эпохи накладывают отпечаток на способ решения интеллектуальных проблем своего времени, на развитие тех или иных мыслительных схем или теоретических конструкций. С. Зенкин описывает «историю идей» как проект развития интеллектуальной истории эпохи модерна, который и определяет особенности гуманитарной культуры современности. Решающий поворот к современности произошел в Новое время, когда анонимную «идею» стали трактовать как авторскую «мысль», таким образом появляется субъективное измерение гуманитарного дискурса. «Когда в Новое время «идею» стали трактовать не как существующий сам по себе прообраз вещей, а как субъективную «мысль», у которой есть автор и обстоятельства возникновения, то на этой основе стало возможно появление истории идей» [7; 70-71].

История идей совершила переворот в гуманитарном дискурсе, поскольку не только обозначила «субъективный» контекст мысли, но также создала тот «культурный фон», благодаря которому вообще стало возможным изучение культуры. Институт интеллектуальной собственности, возникший в Европе в XVIII веке, ввел в обиход новое понимание «идеи» и это стало новой формой интеллектуального дискурса современности. «Как только идея спустилась на землю и оторвалась от вечных сущностей, идеи истинные и ложные очутились рядом... все в целом такое состояние секуляризованных, присвоенных людьми, исторически подвижных и относительных продуктов мысли может быть названо культурой. История идей - едва ли не самая чистая «наука о куль- 
туре», поскольку она может заниматься только культурой, только идеями в их «культурном» (историческом) состоянии» [7; 71]. Эволюция понятия «идея» заложила основы научного изучения «теории» в качестве той интеллектуальной задачи, которая, по мысли С. Зенкина, стоит сегодня перед гуманитарным дискурсом.

Интеллектуальный дискурс современности вынужден преодолевать негативные последствия «ложного сознания», которое «...чаще всего создавалось не с чисто научными, а с социально-критическими целями» $[7 ; 71]$ и которое, по С. Зенкину, имеет три наиболее распространенные формы: предрассудок, идеология и симулякр. Каждая из этих форм имеет свою амбивалентную форму, темпоральную структуру, а также возможности художественной переработки. Не вдаваясь в подробности проведенного С. Зенкиным анализа форм эволюции «ложного сознания», укажем их влияние на современную гуманитарную культуру.

«Рассмотренные три концепции («ложного сознания» А.Е.) включаются в более общее движение новоевропейской мысли - в рефлексию о факторах мнимости, негативности, небытийности, которая развивается в различных направлениях современной философии. Среди перекликающихся с ними концепций можно назвать: (1) понятие необходимых для человеческого сознания «фикций», разрабатываемое в книгах Ницше; (2) философию «как бы», сформулированную в 1870-е годы Х. Файхингером; (3) теорию «возможных миров», разрабатываемую в современной логике и эпистемологии и прилагаемую к теории литературы» [7; 84-85]. Конечно, можно назвать и другие проявления последствий влияния ложного сознания на современный гуманитарный дискурс, но достаточно и приведенных примеров. В этой связи можно согласиться с Зенкиным, который говорит о необходимости преодоления данных форм, затрудняющих развитие интеллектуальной истории идей, и называет те три области гуманитарного знания, где данное преодоление возможно. «Их можно соотнести с методами и задачами трех разных гуманитарных дисциплин: для предрассудков это логика; для идеологем - социология; для симулякров же это современная семиотика и эстетика» [7; 85]. Объединяет эти три гуманитарные области все та же интеллектуальная история, теоретические концепты которой развивает С. Зенкин в своих работах.

«История идей» имеет длительную историю своего развития, начиная с древнегреческой постановки проблемы и заканчивая классическим периодом ее решения [9]. Это означает, что идея возникает достаточно непредсказуемо из различных случайных элементов, у нее потеряна верификационная связь с реальностью, поэтому история идей - это также история заблуждений, иллюзий и прочих форм «ложного сознания». В этой связи требуются вполне определенные «мыслительные схемы», которые помогут локализовать историю идей в формах современного гуманитарного дискурса.

\section{2. Коншептуальный фрейм теории С. Зенкина}

В качестве методологического фрейма понимания подхода С. Зенкина можно использовать теорию «концептов» Ж. Делеза, который считал, что задача философии - формировать концепты. «Создавать новые концепты, которые были бы необходимыми, всегда было задачей философии. Но дело в том, что концепты не являются некими общими идеями, носящимися в воздухе. Напротив, именно сингулярности реагируют на потоки ординарного мышления: в мышлении можно прекрасно обходиться и без концептов, но как только появляется концепт, рождается и подлинная философия» [4; 50]. Различая два плана выражения в философии - трансцендентный (выходящий за пределы опыта) и имманентный (непосредственно присущий внутреннему содержанию философской традиции), Ж. Делез настаивает на том, что философия как творчество концептов является «внутренним делом», т. е. принадлежностью плана имманентности. Это означает, что философия должна отказаться от попыток обнаружить истину «в последней инстанции», отыскать бессмертные идеи или дать ответы на вечные вопросы. Философия должна заниматься простыми вещами, событиями и обстоятельствами, сопутствующими жизни человека (даже если он всего-навсего обыватель). Возможно, что занятие «простыми вещами» выведет философию за ее собственные пределы, сделает ее маргинальной практикой, наподобие некоторых видов живописи или музыки. Это и есть «обратная сторона» процесса захвата территории со стороны философии, когда она, казалось бы, перестает быть сама собой, когда она становится маргинальной практикой и, собственно говоря, процессом производства концептов. В этом, по мысли Ж. Делеза, и проявляется творческая сила философских концептов, теряющих и обретающих себя в пространстве имманентного выражения субъектом самого себя.

«Философ - друг концепта, он находится в потенциальной зависимости от концепта. Это значит, что философия - не просто искусство формировать, изобретать или же изготавливать концепты, ибо концепты - это не обязательно формы, находки или продукты. Точнее будет сказать, что философия - дисциплина, состоящая в творчестве концептов» [3; 13-14]. Предметом философии является чистое творчество концептов, поэтому философ - прежде всего творец, который находится в потенциальной зависимости от своего творения. Задача философа - творить все новые концепты, убеждать других пользоваться ими, а также сомневаться в качестве других концептов, сотворенных до него. Каждый более или менее крупный философ является творцом концеп- 
тов, за которыми стоит его подпись и которыми пользуются другие.

Именно поэтому философия не является ни созерцанием, ни рефлексией, ни коммуникацией, поскольку это иллюзии, которыми философия прикрывала свою концептуальность. Ж. Делез и Ф. Гваттари аргументированно доказывают, почему философия не является ни созерцанием (оно суть сами же вещи в ходе творения соответствующих концептов), ни рефлексией (называя философию искусством размышления, ее принижают, рефлексивность столь же присуща и математикам, и художникам), ни коммуникацией (поскольку избегает консенсуса мнений). "Созерцание, рефлексия и коммуникация - это не дисциплины, а машины, с помощью которых в любых дисциплинах образуются Универсалии... первейший принцип философии состоит в том, что Универсалии ничего не объясняют, они сами подлежат объяснению» [3; 15-16].

Философия в своем развитии прошла этап господства над другими дисциплинами через создание универсалий, помогающих другим наукам концептуализировать собственные основания. Но не следует забывать, что творчество (в том числе творчество концептов в философии) всегда есть нечто единичное, сингулярное, поэтому универсальность философских концептов ничего не объясняет, но только запутывает существо дела. С помощью концепта можно нечто познавать только в том случае, если философ сам является его творцом, другом концепта, об этом говорил еще Ф. Ницше. Таким образом, вопрос о пользе или вреде философии ставится совсем по-другому. Философия не должна испытывать потребности оправдываться относительно собственной отвлеченности или бесполезности, равно как пытаться доминировать в той или иной сфере человеческой деятельности (науке, религии, искусстве или политике). Истинная задача философской деятельности - творчество концептов, и до тех пор, пока «друзья концептов» (философы) будут творить все новые концепты, философия не будет знать своего предела.

С. Зенкин, будучи переводчиком, подарившим русскоязычному читателю ключевую работу Ж. Делеза и Ф. Гваттари «Что такое философия?» (1998, рус. перев.), высоко оценивает вклад французского мыслителя в проблему концептуальности интеллектуального дискурса. «Некоторые современные мыслители уже обращали внимание на то, как важны в развитии интеллектуальной культуры случайные, уникально-неподражаемые и вовлеченные во временное становление модели. Так, Жиль Делез определял философские концепты как сложные и «шифрованные» конфигурации элементов, составляемые конкретным мыслителем в конкретной ситуации... Для истории идей полезно будет учесть эту философскую концепцию, применяя ее к своим соб- ственным задачам» [7; 88].

Таким образом, на примере идей Ж. Делеза о «концептуальности» философии можно увидеть непосредственную работу интеллектуального фрейма в теории С. Зенкина, который успешно инкорпорировал ключевую работу Ж. Делеза и Ф. Гваттари в российское интеллектуальное пространство, где она нашла как своих апологетов, так и противников [5].

\section{3. Мыслительные схемы в гуманитарной культуре современности}

«Мыслительные схемы», которые предлагает С. Зенкин в качестве тех концептов, которые помогают понять историю идей и эволюцию интеллектуального дискурса современности носят, по всей видимости, трансдискурсивный характер. Они, с одной стороны, генетически связаны с некой «идеей», которую призваны воплощать, а с другой, постоянно мигрируют между различными дискурсами, создавая ситуации «непереводимости». «Абстрактность, содержательную незакрепленность мыслительных схем следует понимать двояко: как их относительную независимость от временного развития и как их способность к преодолению дискурсивных и дисциплинарных границ. «Легкие», не отягощенные фиксированным субстанциальным содержанием мыслительные схемы свободны от дисциплинарной фиксации и проникают в различные поля интеллектуальной культуры. В то время как философские концепты часто с трудом поддаются переводу с одного на другой национальный язык, эти схемы гораздо проще могут быть перенесены в другой язык и пересказаны другими словами» [7; 88].

С. Зенкин предлагает три серии примеров, иллюстрирующих функционирование мыслительных схем в гуманитарном дискурсе конца XIX - начала XX века. Первая серия носит название «иерархический переворот»: «В рамках такой мыслительной схемы имеется две смысловые инстанции, которые подчинены одна другой, но в какой-то момент их отношение обращается, или по крайней мере «низший» элемент прорывается вверх, несмотря на сопротивление доминирующего» [7; 88-89]. В качестве примера автор приводит диалектику господина и раба в «Феноменологии духа» Г. Гегеля, теорию бессознательного 3. Фрейда, «карнавальную культуру» М. Бахтина. Вторая серия называется «неоднородное поле»: «...в рамках такой схемы описываемые факты изображаются в виде поверхности или пространства, где некоторые точки выделены, выступая на фоне других, нейтральных» [7; 90]. Примерами функционирования неоднородного поля как мыслительной схемы может являться теория психики Ж. Лакана (с ее делением на реальное, воображаемое и символическое), семиотическая теория моды Р. Барта и понятие «места памяти» «...предложенное Пьером Нора и означающее определенные (не обя- 
зательно географические) точки реальности, в которых сосредоточена память данного общества о прошлом и которые выделяются на фоне беспамятного или внепамятного пространства, пространства забвения» [7; 91]. Третья серия у С. Зенкина получила название «градуальное распределение». Данная мыслительная схема достаточно разработана А. Лавджоем и М. Фуко. «Градуальное распределение имеет форму шкалы, вдоль которой могут перемещаться отдельные элементы (человеческий дух восходит по «великой цепи бытия», девиантное поведение последовательно корректируется, приводится к норме под действием дисциплинарных мер)» [7; 91].

Проблема, на которую указывает С. Зенкин состоит в том, какого рода знанием (или концептуальным элементом) являются описанные мыслительные схемы. Вполне очевидно, что они уже не являются «идеями», равно как понятиями или «пропозициями», могущими быть проверенными на предмет истинности или ложности. Они слишком абстрактны, чтобы стать «метафорами» или «образами» (хотя их создатели вынуждены использовать метафорический язык), к ним не подходит определение «миф» или «нарратив». «Мыслительные схемы приходится воображать, а не просто мыслить. Пользуясь мыслительными схемами, мы чаще всего не сознаем этого и вообще не даем им достаточно обобщенного названия. Вместе с тем очевидно, что мыслительные схемы, хоть и не являются сами по себе идеями, лежат в основе важнейших идей современности» [7; 92].

Дискурсивные особенности современной мысли говорят нам о том, что проблема текста (в том числе философского) должна решаться с привлечением более широкого интеллектуального контекста. Например, используя «мыслительные схемы» в качестве концептуальных единиц знания. «По-видимому, мыслительные схемы служат матрицами, порождающими моделями, чьи возможности богаче, чем реальные концептуальные построения, создаваемые на их основе. Они фундаментально важны для нашей умственной работы - но по самой своей природе не поддаются категоризации; скорее их можно было бы охарактеризовать как фигуры - одновременно в гештальтпсихологическом и риторическом смысле слова» [7; 92]. Здесь можно согласиться с мнением С. Зенкина, поскольку текстологический и дискурсивный объем используемого в мыслительной схеме знания с одной стороны требует развитого «воображения» (ведь их невозможно «мыслить»), а с другой, богатого арсенала языковых средств и риторических приемов. Фигуративность мыслительных схем также наводит на мысль относительно их топологической структуры и способа существования, поскольку пространственная логика их понимания и выражения более чем очевидна [5].

Фигуративность мыслительных схем также предполагает, по мысли С. Зенкина, использование методов и приемов поэтики, понимаемой им в качестве «науки о фигурах». Отсюда и возникает программа «поэтики интеллектуального дискурса», которая в основных своих положениях отличается от «истории идей», и которая является наиболее востребованной формой современной гуманитаристики на Западе. «Если обычная история идей имеет дело по преимуществу с близкими отношениями преемственности, полемики, взаимообмена между интеллектуальными высказываниями, то есть с отношениями, возникающими при документируемых, доказуемых контактах между текстами и авторами, то поэтика интеллектуального дискурса изучает более далекие, дистантные отношения, которые труднее проследить известными нам методами, но которые часто весьма продуктивны и значимы в интеллектуальной жизни той или иной эпохи» [7; 93].

Другая, не менее важная проблема, на которую указывает С. Зенкин, заключается в том, почему описанные мыслительные схемы носят ярко выраженный «современный» характер, ведь можно увидеть и более отдаленные исторические проявления их логики. Ответ на поверхности, во-первых, это действительно так (история данных схем уходит глубоко в прошлое), и поэтому эволюция мыслительных схем сопоставима с эволюцией основных понятий гуманитарной мысли, требованиями «обновления словаря». А во-вторых, ослабление «концептуальности» В мышлении современной эпохи приводит к тому, что необходимо заново изобретать данные концепты, чтобы сделать мысль внятной и адекватной происходящим в современной культуре процессам. «Впечатление такое, что именно современная эпоха особенно склонна пользоваться неконцептуальными, нелогическими порождающими моделями, мыслительными схемами нарративно-временного или визуально-пространственного типа, и не случайно, что именно современная культура так активно занимается теоретическим осмыслением нарративных и визуальных (образных) представлений» [7; 94]. Попросту говоря «визуальный сдвиг» современной культуры сделал ее менее концептуальной и понятийной; «клиповое мышление» (Ф. Гиренок) современной эпохи дискредитирует философский дискурс и требуется дать ответ на возникшую ситуацию.

В этой связи примечательным является подход Ф. Гиренка, который описывает современный российский интеллектуальный дискурс в целом, и философский в частности, следующим образом:

«Современное состояние философии в России определяется, на мой взгляд, следующими обстоятельствами:

1. скрытым конфликтом между двумя дискурсами русским и советским;

2. противостоянием философского способа мышления и научного;

3. поиском философией ответов на вопросы, кото- 
рые поставлены фактом существования виртуальных практик и актуального искусства;

4. осознанием того факта, что на место сознания встал язык. Это главное событие в философии XXI века;

5. обнаружением пределов понятийного сознания и разработкой теории клипового сознания;

6. 6) поисками антропологического «бозона», который виртуальное превращает в реальное;

7. переосмыслением разумности человека и концептуальный отказ от идеи логоса в пользу идеи абсурда» [2; 35-36].

Думается, что решение обозначенных проблем и предопределит динамику развития российской гуманитарной культуры, решающую роль в становлении которой будет играть философия посредством развития новых способов порождения и потребления значимых для культуры текстов.

\section{ЗакАючение}

Подводя итоги проведенному исследованию, следует сказать, что проблема описания перспектив развития гу- манитарного дискурса современности имеет множество сценариев. Одним из возможных сценариев является подход С. Зенкина, которому мы дали детальный анализ. Обозначим основные «концептуальные единицы» данного подхода. Во-первых, интеллектуальный дискурс современности является отражением логики и динамики развития «истории идей», которая в свою очередь является выражением культурных и социальных процессов в истории человеческой культуры. Во-вторых, интеллектуальная история человечества может рассматриваться как преодоление различных форм «ложного сознания», таких как, предрассудок, идеология и симулякр. Результатом такого преодоления является «мыслительная схема», помогающая адекватно отразить и понять сущность культурных процессов. В-третьих, для анализа особенностей гуманитарного дискурса современности следует использовать различные «фреймы», помогающие контекстуализировать культурный текст, приводить его в соответствие с требованиями времени. Проведенное нами исследование также может рассматривать как «фрейм» работы С. Зенкина, позволяющее более детально репрезентировать значимые для гуманитарной культуры современной России концепты.

ЛИТЕРАТУРА

1. Бибихин В.В. Чтение философии. СПб.: Наука, 2009. 536 с.

2. Гиренок Ф.И. Клиповое сознание. М.: Проспект, 2016. 256 с.

3. Делез Ж., Гваттари Ф. Что такое философия? / Пер. с франц. С.Н. Зенкина. М.: Институт экспериментальной социологии; СПб.: Алетейя, 1998. 288 с.

4. Делез Ж. Переговоры. 1972-1990 / Пер. с фр. В.Ю. Быстрова. СПб.: Наука, 2004. 235 с.

5. Еникеев А.А. Введение в чтение Ж. Делеза. Исследование по поэтике и топологии философского текста. Краснодар: Новация, 2017. 110 с.

6. Еникеев А.А. Проблема чтения и письма в контексте поэтики и прагматики философского текста // Научный журнал КубГАУ. 2016. № 122. С. $867-887$.

7. Зенкин С.Н. Работы о теории: Статьи / Сергей Зенкин. М.: Новое литературное обозрение, 2012.560 c.

8. Ман П. де. Аллегории чтения: Фигуральный язык Руссо, Ницше, Рильке и Пруста: Пер. с англ. / Пер., примеч., послесл. С.А. Никитина. Екатеринбург: Издво Урал. ун-та, 1999. 368 с.

9. Панофски Э. І Іеа: К истории понятия в теориях искусства от античности до классицизма / Пер. с нем. Ю.Н. Попова (изд. 2-е, испр.). СПб.: Андрей Наследников, 2002. 237 c.

10. Подорога В.А. Время чтения / В.А. Подорога. М.: Канон+ РООИ «Реабилитация», 2021. 376 с.

(с Еникеев Анатолий Анатольевич (rizoma69@yandex.ru).

Журнал «Современная наука: актуальные проблемы теории и практики» 